\title{
Complex Gangliosides at the Neuromuscular Junction Are Membrane Receptors for Autoantibodies and Botulinum Neurotoxin But Redundant for Normal Synaptic Function
}

\author{
Roland W. M. Bullens, ${ }^{1,2}$ Graham M. O'Hanlon, ${ }^{3}$ Eric Wagner, ${ }^{3}$ Peter C. Molenaar, ${ }^{2}$ Keiko Furukawa, ${ }^{4}$ \\ Koichi Furukawa, ${ }^{4}$ Jaap J. Plomp, ${ }^{1,2}$ and Hugh J. Willison ${ }^{3}$ \\ Departments of ${ }^{1}$ Neurology and ${ }^{2}$ Physiology, Leiden University Medical Centre, 2300 RC, Leiden, The Netherlands, \\ 3University Department of Neurology, Institute of Neurological Sciences, Southern General Hospital, Glasgow, G51 4TF, \\ Scotland, and ${ }^{4}$ Department of Biochemistry II, Nagoya University School of Medicine, Showa-ku, Nagoya 466-0065, \\ Japan
}

\begin{abstract}
One specialization of vertebrate presynaptic neuronal membranes is their multifold enrichment in complex gangliosides, suggesting that these sialoglycolipids may play a major functional role in synaptic transmission. We tested this hypothesis directly by studying neuromuscular synapses of mice lacking complex gangliosides attributable to deletion of the gene coding for $\beta 1,4$ GalNAc-transferase (GM2/GD2 synthase), which catalyzes an early step in ganglioside synthesis. Our studies show that complex gangliosides are surprisingly redundant for regulated neurotransmitter release under normal physiological
\end{abstract}

conditions. In contrast, we show that they are membrane receptors for both the paralytic botulinum neurotoxin type-A and human neuropathy-associated anti-ganglioside autoantibodies that arise through molecular mimicry with microbial structures. These data prove the critical importance of complex gangliosides in mediating pathophysiological events at the neuromuscular synapse.

Key words: complex gangliosides; neuromuscular junction; synaptic transmission; botulinum neurotoxin; anti-ganglioside antibodies; Miller Fisher syndrome; $\beta 1,4$ GalNAc-transferase
Gangliosides are sialylated glycosphingolipids, concentrated in the outer leaflet of synaptic membranes (Wiegandt, 1967; Hansson et al., 1977; Ledeen, 1978; Simons and Ikonen, 1997). Their diversity is regulated by specific glycosyltransferases (Maccioni et al., 1999) (see Fig. 1). Indirect evidence has suggested a role for endogenous gangliosides in neurotransmitter release (Rahmann et al., 1982). Bath-applied gangliosides increase synaptosomal neurotransmitter release (Tanaka et al., 1997; Ando et al., 1998) and modulate post-tetanic and long-term potentiation (Wieraszko and Seifert, 1985; Ramirez et al., 1990; Egorushkina et al., 1993; Furuse et al., 1998). Furthermore, gangliosides coexist with exocytotic soluble $N$-ethylmaleimide-sensitive factor attachment protein receptor (SNARE) proteins in membrane lipid rafts (Chamberlain et al., 2001; Lang et al., 2001) and can influence ion-channel function (Kappel et al., 2000).

In botulism, gangliosides might form presynaptic ectoacceptors at the neuromuscular junction (NMJ) for clostridial botulinum neurotoxins that are internalized and then enzymatically cleave SNARE proteins, resulting in block of acetylcholine (ACh) release and paralysis (Simpson, 1989; Schiavo et al., 1992, 2000; Ahnert-Hilger and Bigalke, 1995). This role for polysialogangliosides is suggested by in vitro binding experiments and blocking

Received Jan. 15, 2002; revised May 23, 2002; accepted May 23, 2002.

R.W.M.B. was sponsored by the Prinses Beatrix Fonds (62-0210, granted to P.C.M.). This work was further supported by grants from the Koninklijke Nederlandse Akademie van Wetenschappen Van Leersumfonds (J.J.P.), the Stichting "De Drie Lichten" (R.W.M.B.), and the Wellcome Trust (060349) (H.J.W.).

Correspondence should be addressed to Dr. Jaap J. Plomp, Department of Physiology, Leiden University Medical Centre, Wassenaarseweg 62, P.O. Box 9604, 2300 RC, Leiden, The Netherlands, E-mail: j.j.plomp@lumc.nl, or Dr. Hugh J. Willison, University Department of Neurology, Institute of Neurological Sciences, Southern General Hospital, Glascow, G51 4TF, Scotland, E-mail: h.j.willison@udcf.gla.ac.uk.

Copyright (C) 2002 Society for Neuroscience 0270-6474/02/226876-09\$15.00/0 studies using lectins (Simpson and Rapport, 1971a,b; Kitamura et al., 1980; Bigalke et al., 1986; Takamizawa et al., 1986; Marxen et al., 1989; Bakry et al., 1991; Ginalski et al., 2000; Singh et al., 2000).

Botulism clinically resembles the paralytic neuropathy termed Miller Fisher syndrome (MFS), a variant of the Guillain-Barré syndrome (GBS) (Fisher, 1956). MFS is often anteceded by Campylobacter jejuni infection, and most patient sera contain anti-ganglioside-GQ1b/GT1a antibodies that arise through immune response to ganglioside-like structures on bacterial lipopolysaccharides (Chiba et al., 1993; Yuki et al., 1993; Goodyear et al., 1999; Willison and O'Hanlon, 1999).

In view of the clinical resemblance between MFS and botulism, and the NMJ being the known botulinum neurotoxin target, the pathogenic effects of MFS sera and anti-GQ1b antibodies have been studied at mouse NMJs (Roberts et al., 1994; Buchwald et al., 1998; Goodyear et al., 1999; Plomp et al., 1999). One suggested pathophysiological mechanism is that anti-GQ1b antibodies bind to presynaptic GQ1b and induce a complementdependent, transient, and dramatic increase in spontaneous ACh release, followed by block of evoked release (Goodyear et al., 1999; Plomp et al., 1999; Bullens et al., 2000). This effect resembles that of $\alpha$-Latrotoxin ( $\alpha \mathrm{LTx}$ ), and is accompanied by presynaptic destruction (O'Hanlon et al., 2001). However, there is no direct evidence that GQ1b or a similar complex ganglioside is the autoantibody receptor.

Thus, presynaptic gangliosides may be involved in transmitter release, botulinum neurotoxin action, and autoimmunity, but direct proof is lacking. To address these issues directly, we studied mice lacking the gene coding for the glycosyltransferase, $\beta 1,4$ GalNAc-transferase ( $\beta 1,4$ GalNAc-T; GM2/GD2 synthase; EC 2.4.1.92) (Takamiya et al., 1996). In these mice, complex ganglio- 
sides including GQ1b are absent. Consequently, neuronal membranes bear only simple gangliosides GD3 and GM3 (see Fig. 1), the expression of which is upregulated (Takamiya et al., 1996). Here, we show that complex gangliosides are redundant for basic synaptic transmission and prove that they are biologically significant membrane receptors for botulinum neurotoxin and form primary antigenic targets for neuropathy-related autoantibodies.

\section{MATERIALS AND METHODS}

Mice. GalNAc- ${ }^{+/-}$mice were bred, and their progeny were genotyped as described previously (Takamiya et al., 1996). GalNac- ${ }^{-1-}$ mice lack complex gangliosides (Fig. 1). All animal experiments were performed according to Dutch and United Kingdom laws and Leiden and Glasgow University guidelines (DEC 00036; PPL 60/2305). GalNAc-T ${ }^{+/+}$mice (and on occasion GalNAc- ${ }^{+/-}$mice, as indicated in Results) were used as controls. Ten- to 15-week-old mice were killed by $\mathrm{CO}_{2}$ inhalation. Left and right hemi-diaphragms with their phrenic nerve attached were dissected and mounted in a dish containing Ringer's solution composed of (in mM): $116 \mathrm{NaCl}, 4.5 \mathrm{KCl}, 1 \mathrm{MgCl}_{2}, 2 \mathrm{CaCl}_{2}, 1 \mathrm{NaH}_{2} \mathrm{PO}_{4}, 23 \mathrm{NaHCO}_{3}$, 11 glucose, $\mathrm{pH} 7.4$, at room temperature $\left(20-22^{\circ} \mathrm{C}\right)$, pre-gassed with $95 \%$ $\mathrm{O}_{2} / 5 \% \mathrm{CO}_{2}$.

In vitro electrophysiology. Microelectrode recordings were performed as described previously (Bullens et al., 2000). Briefly, microelectrode impalements were made at the endplate region of muscle fibers in preparations that had been treated with $3 \mu \mathrm{M} \mu$-Conotoxin GIIIB (Scientific Marketing, Barnet, UK) to eliminate muscle action potentials by selective block of muscle $\mathrm{Na}^{+}$channels (Cruz et al., 1985). Synaptic electrophysiological signals were recorded in 10-15 NMJs, chosen randomly within the preparation. At each NMJ, the nerve stimulationevoked endplate potentials (EPPs) and spontaneous miniature EPPs (MEPPs) were recorded. Signals were digitized and analyzed using a Digidata 1200 interface and the Clampex 7 and Clampfit programs, all from Axon Instruments (Union City, CA) and using routines programmed in Matlab (The MathWorks, Natick, MA).

EPPs and MEPPs were recorded in Ringer's solution unless stated otherwise. For oxygenation, $95 \% \mathrm{O}_{2} / 5 \% \mathrm{CO}_{2}$ was blown over the surface of the $2 \mathrm{ml}$ incubation medium. The mean amplitudes of EPPs and

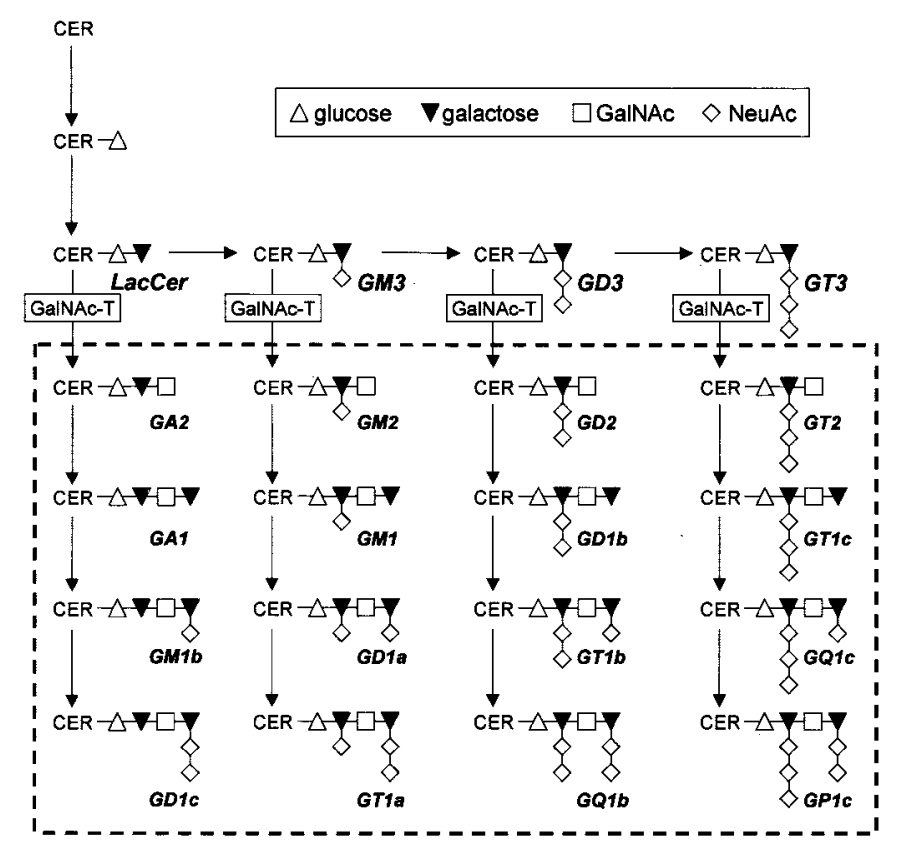

Figure 1. Ganglioside biosynthesis. In the investigated GalNAc- ${ }^{-1-}$ mice, disruption of the $N$-acetylgalactosaminyl-transferase (GalNAc-T) gene results in the absence of all the complex gangliosides within the dashed rectangle (Takamiya et al., 1996). Ganglioside nomenclature is according to Svennerholm (1994). CER, Ceramide; GalNAc, N-acetylgalactosamine; LacCer, lactosylceramide; $N e u A c$, neuraminic acid or sialic acid.
MEPPs at each NMJ were normalized to $-75 \mathrm{mV}$ by using the formula $A_{\text {norm }}=\mathrm{A} \times\left(-75-E_{\mathrm{r}}\right) / E_{\mathrm{m}}$, where $A$ is the mean measured amplitude of EPP or MEPP in millivolts, $A_{\text {norm }}$ is the normalized amplitude, $E_{\mathrm{r}}$ is the reversal potential for ACh-induced current (assumed to be 0 ) (Magleby and Stevens, 1972), and $E_{\mathrm{m}}$ is the mean resting membrane potential during the period of measurement. The EPP amplitudes were also corrected for nonlinear summation (McLachlan and Martin, 1981). The quantal content, i.e., the number of ACh quanta released after a single nerve impulse, was calculated at each NMJ by dividing the mean normalized and corrected EPP amplitude by the mean normalized MEPP amplitude.

Basic NMJ electrophysiology was characterized at a range of temperatures $\left(17,20,30\right.$, and $\left.35^{\circ} \mathrm{C}\right)$, in view of the possibility that complex gangliosides play a role in thermal adaptation and stabilization of ion channel function (Rahmann et al., 1998; Kappel et al., 2000). We performed several series of temperature experiments with different batches of mutant mice. In one series of experiments, all measurements were done at $20^{\circ} \mathrm{C}$; in another series, each preparation was analyzed at $35^{\circ} \mathrm{C}$; and in a further separate series, preparations were tested at both 17 and $30^{\circ} \mathrm{C}$. In the latter series we varied between the preparations the order in which the two different temperatures were tested. In each of the different temperature experiments series, a matching amount of wild-type and heterozygous controls were included. We modified temperature using a Peltier device placed around the recording bath and monitored the bath temperature with a miniature thermocouple probe that was connected to a digital thermometer. The temperature was adjusted manually via the power supply of the Peltier element.

Furthermore, the concentration of $\mathrm{Ca}^{2+}$ in the medium was varied $\left(0.5,2\right.$, and $5 \mathrm{mM}$, at the fixed temperature of $\left.20^{\circ} \mathrm{C}\right)$, in view of the ability of complex gangliosides to sequester this cation (Rahmann et al., 1998).

Miller Fisher syndrome serum and mouse anti-GQ1b/GD3 monoclonal antibodies. We tested the ability of anti-ganglioside $\operatorname{IgM}$ and $\operatorname{IgG}$ mouse monoclonal antibodies (mAbs) and MFS patient serum containing antiGQ1b IgG (serum titer 1:3600) (Willison et al., 1993) to induce the $\alpha \mathrm{LT}$ x-like effect at NMJs of GalNAc- ${ }^{-1-}$ and control NMJs. Serum was heated (for $30 \mathrm{~min}$ at $56^{\circ} \mathrm{C}$ ) to inactivate complement. The mouse mAbs (CGM3, EM6, CGG1, and CGG2; each reactive with either GQ1b or GD3, or both) were derived using standard hybridoma techniques from mice immunized with lipopolysaccharides that contained GD3/GT1alike structures and originated from MFS/GBS-associated Campylobacter jejuni strains (Goodyear et al., 1999). Their specific anti-ganglioside activity was determined by ELISA using purified GM1, GM2, GM3, GD1a, GD1b, GD3, GT1b, and GQ1b and is given in Table 1.

Incubations with antibodies and toxins. Hemi-diaphragms were incubated with either the complement-inactivated MFS serum (diluted 1:2) or $50 \mu \mathrm{g} / \mathrm{ml}$ of the mouse mAb CGM3, EM6, CGG1, or CGG2. Serum and antibodies were diluted with, and dialyzed against, Ringer's before their experimental use. The incubation procedure comprised a 3-4 hr incubation in $1.5 \mathrm{ml}$ medium in a capped vial at $32^{\circ} \mathrm{C}$ followed by a $30-45$ min period at $4-8^{\circ} \mathrm{C}$. The cooling period was included in view of the facilitated binding of anti-ganglioside antibodies to antigen at lower temperature (Willison et al., 1993). After the incubation, MEPPs were recorded in fresh Ringer's solution at room temperature. Next, serum (diluted 1:2 and dialyzed against Ringer's) from healthy subjects was added as a complement source, and we observed with further MEPP recordings whether the $\alpha \mathrm{LTx}$-like effect appeared. In cases in which the antibodies lacked effect, $\alpha$ LTx (4 nM; Alomone Laboratories, Jerusalem, Israel) was later applied as positive control. In all cases, the $\alpha \mathrm{LTx}$ readily induced its effect, i.e., a dramatic increase in the spontaneous ACh release, measured as MEPP frequency (data not shown).

In a first series of experiments, botulinum neurotoxin type-A (Botox, Allergan, Nieuwegein, The Netherlands) was applied in the clinically used spasmolytic concentration of 50 Allergan $\mathrm{U} / \mathrm{ml}$, equivalent to $\sim 2 \mathrm{ng} / \mathrm{ml}$ of the toxin. One Allergan unit corresponds to the calculated median intraperitoneal lethal dose, $\mathrm{LD}_{50}$, in mice. Hemi-diaphragms were preincubated in a small capped vial with $1.5 \mathrm{ml}$ botulinum neurotoxin solution in Ringer's for $4 \mathrm{hr}$ at $32^{\circ} \mathrm{C}$ without nerve stimulation. This allowed for binding of the toxin to its membrane receptor. Thereafter, unbound botulinum neurotoxin was washed away, and the preparation was mounted into the in vitro electrophysiological setup in fresh Ringer's at $35^{\circ} \mathrm{C}$, with added $\mu$-conotoxin to eliminate muscle action potentials. The phrenic nerve was stimulated for $45 \mathrm{~min}$ at $1 \mathrm{~Hz}$ to induce incorporation of bound toxin into the nerve terminals. Thereafter, $\mu$-conotoxin was washed away and EPPs and MEPPs were recorded at $25^{\circ} \mathrm{C}$, as described above. In a following series of experiments, higher 
concentrations $(20,200$, and $600 \mathrm{ng} / \mathrm{ml})$ of botulinum neurotoxin type-A were each tested at three wild-type and three GalNAc- $^{-1-}$ nerve muscle preparations. Because these high concentrations could not be made up from BOTOX, we used toxin purchased from Calbiochem (1 $\mu \mathrm{g} / \mu \mathrm{l}$ stock solution). The same incubation protocol as described above was used.

Muscle contraction experiments. We quantified the extent of paralysis caused by the mouse mAbs CGM3 and EM6 by recording in vitro isotonic contraction with a force transducer at room temperature $\left(20-24^{\circ} \mathrm{C}\right)$. Left phrenic nerve hemi-diaphragms from GalNAc- ${ }^{-1-}$ and wild-type mice were first preincubated with the mAbs, as described above, and subsequently mounted in the contraction chamber. The phrenic nerve was stimulated supramaximally once every 5 min with a train of 80 stimuli at $40 \mathrm{~Hz}$, during a $25 \mathrm{~min}$ period in Ringer's medium and subsequent periods of 20 and $60-120 \mathrm{~min}$ in complement-inactivated and complement-containing normal healthy serum $(1: 2)$, respectively. The medium (1.5 ml volume) was gently bubbled with $95 \% \quad \mathrm{O}_{2} / 5 \% \quad \mathrm{CO}_{2}$ throughout the experiment.

Immunohistology. After the electrophysiological experiments were completed, the diaphragms were cut parallel with the fiber direction into small strips, snap frozen in vials placed on dry ice, and stored at $-80^{\circ} \mathrm{C}$ for subsequent immunohistological analysis. Tissue was mounted in Lipshaw's M-1 mounting medium (Pittsburgh, PA), and $7 \mu \mathrm{m}$ cryostat sections were cut onto 3-aminopropyltriethoxysilane-coated slides and allowed to air dry before use or storage at $-20^{\circ} \mathrm{C}$. The samples were rinsed and then incubated with fluorescence-labeled anti-mouse IgM or IgG antibodies (Southern Biotechnology Associates, Birmingham, AL) diluted 1:300 in PBS for $1 \mathrm{hr}$ at $4^{\circ} \mathrm{C}$. To identify NMJs, bodipy- or Texas Red-labeled $\alpha$-bungarotoxin (BTx) ( 1 or $0.5 \mathrm{mg} / \mathrm{ml}$, respectively; Molecular Probes, Leiden, The Netherlands), which labels the postsynaptic $\mathrm{ACh}$ receptor, was included in the solution. After all incubations, slides were rinsed in PBS, mounted in antifade solution (Citifluor, Canterbury $\mathrm{UK}$ ), and stored at $4^{\circ} \mathrm{C}$ in the dark before viewing. To identify complement deposition at the NMJ, unfixed tissue sections were incubated for 1 hr at $4^{\circ} \mathrm{C}$ with FITC-labeled anti-complement C3c (diluted 1:300; Dako, Ely, UK) in PBS containing 10\% goat serum and Texas Red-labeled BTx.

We also performed quantitative immunohistological analysis of immunoglobulin (CGM3, CGG1, CGG2, EM6) binding to NMJs of three GalNAc- $\mathrm{T}^{->-}$and three wild-type untreated diaphragms that were not investigated electrophysiologically. To this end, $7 \mu \mathrm{m}$ cryosections were incubated overnight with $20 \mu \mathrm{g} / \mathrm{ml} \mathrm{mAb}$ in PBS containing $10 \%$ goat serum at $4^{\circ} \mathrm{C}$, and processed further as described above.

Image acquisition and analysis of the NMJ. Digital images were captured by a Zeiss Pascal confocal microscope. Image-analysis measurements were made using Scion Image (Scion Corporation) or Aequitas IA (Dynamic Data Links, Cambridge, UK) software.

NMJs were identified on the basis of BTx staining, and images of the BTx and associated immunoglobulin or complement stain were recorded under standardized camera conditions. The signal directly overlaying the BTx-labeled area was measured and expressed as a percentage of that area using an image analysis procedure described elsewhere (O'Hanlon et al., 2001). Because these numerical data are ultimately dependent on technical settings that vary between antibodies and experiments, limited inference can be made from the absolute values and after sample decoding data were converted to a percentage of the mean value of an internal standard. For anti-ganglioside antibody binding studies, this standard was the signal obtained from GalNAc- $\mathrm{T}^{+/+}$tissue. In the case of complement deposition studies, the signal of control NMJs treated with CGM3 and EM6 was used as the standard (see legend of Fig. 7B). The data shown are the combined results from at least three different staining runs.

Statistics. The data are presented as the grand mean \pm SEM of the mean values obtained from the individual muscles in a test group. Possible statistical differences were analyzed with an unpaired Student's $t$ test, wherever appropriate.

\section{RESULTS}

\section{Characterization of neuromuscular synapse electrophysiology in GalNAc-T ${ }^{-1-}$ mice}

The putative role of complex gangliosides in modulating synaptic transmission was first tested in microelectrode studies performed at $20^{\circ} \mathrm{C}$ in GalNAc- ${ }^{-1-}$ NMJs. Presynaptic ACh release evoked by low- $(0.3 \mathrm{~Hz})$ or high-rate $(40 \mathrm{~Hz})$ nerve stimulation, as well as the spontaneous release (measured as the frequency of MEPPs),
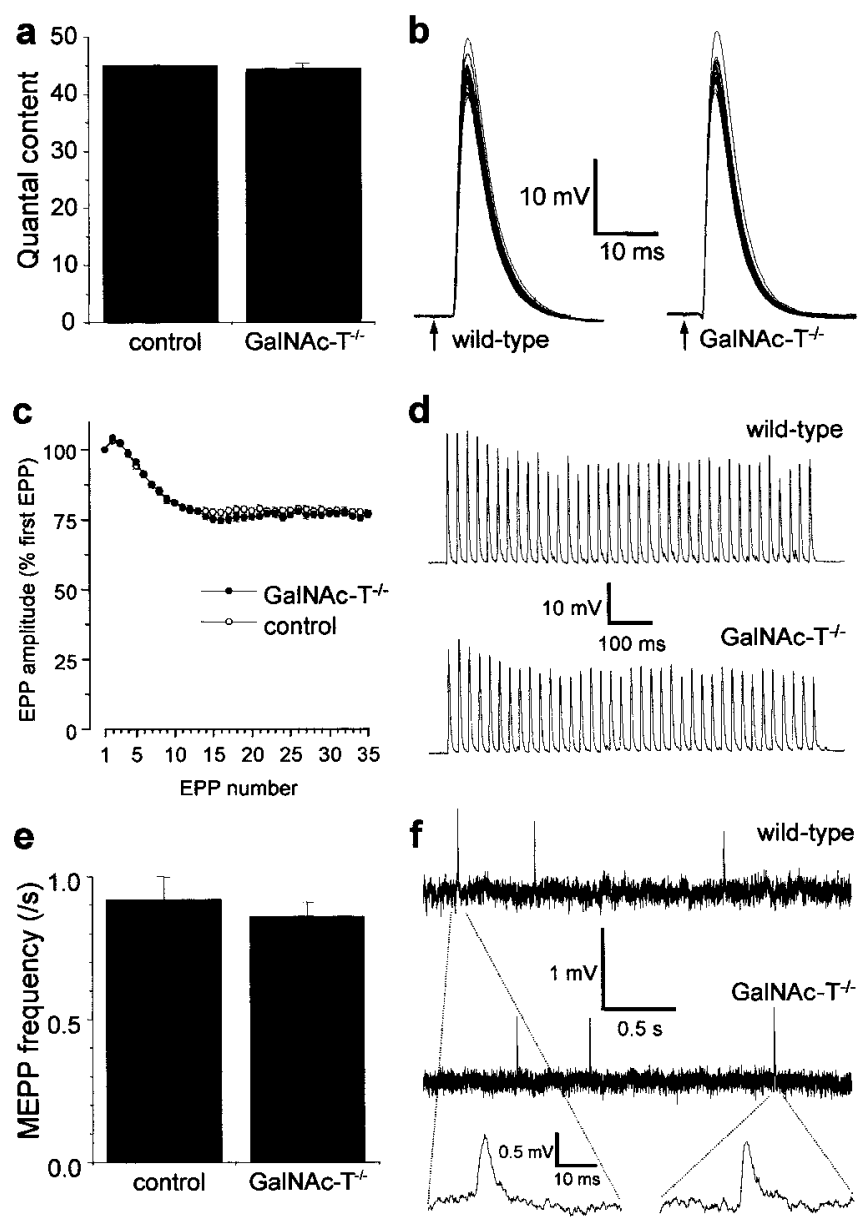

Figure 2. Basic synaptic electrophysiology at GalNAc- ${ }^{-/-}$neuromuscular junctions. Measurements were performed at $20^{\circ} \mathrm{C}$ in diaphragms of six GalNAc- $\mathrm{T}^{-/-}$and six control ( 3 wild-type and 3 heterozygous) mice. No significant differences were observed in nerve stimulation-evoked and spontaneous ACh release. $a$, Quantal content of the endplate potential $(E P P)$ at $0.3 \mathrm{~Hz}$ nerve stimulation. $b$, Typical examples of recorded EPPs; 30 consecutive EPPs at $0.3 \mathrm{~Hz}$ have been superimposed. The resting membrane potential during these measurements was found to be similar at wild-type and GalNAc-T ${ }^{-1-}$ NMJs $(-75.2 \pm 0.5$ and $-74.6 \pm 0.2 \mathrm{mV}$, respectively; means \pm SEM; $p=0.24)$. The moment of nerve stimulation is indicated with an arrow. $c$, Average profiles of ACh release evoked by $40 \mathrm{~Hz}$ nerve stimulation. $d$, Typical examples of recorded EPP trains during $40 \mathrm{~Hz}$ stimulation. $e$, Spontaneous ACh release, measured as the frequency of miniature endplate potentials $(M E P P)$, the spontaneous uniquantal events. $f$, Typical examples of recordings of MEPPs. No differences in amplitude or shape of MEPPs were observed. Error bars in $a, c$, and $e$ represent $\mathrm{SE}$ of the grand mean values in each group.

did not differ from that observed in the control $\left(\right.$ GalNAc- $\mathrm{T}^{+/-}$ and GalNAc- ${ }^{+/+}$) preparations (Fig. 2). This indicates a redundancy of complex gangliosides for transmitter release under these circumstances. Similarly, MEPP characteristics were unchanged (Fig. 2). The mean amplitude was $0.87 \pm 0.07$ and $0.86 \pm 0.05 \mathrm{mV}$ at control and GalNAc-T ${ }^{-1-}$ NMJs, respectively. The mean width of MEPPs at $50 \%$ of their peak amplitude was $2.58 \pm 0.08$ and $2.28 \pm 0.13 \mathrm{msec}$ at control and GalNAc- ${ }^{-1-}$ NMJs, respectively (mean $\pm \mathrm{SEM} ; p=0.29$ ). These results indicate indirectly that complex gangliosides are not involved in the induction or maintenance of postsynaptic $\mathrm{ACh}$ receptor clustering or in receptor function and do not influence the electrical resistance and capacitance of the muscle fiber membrane.

Because the modulating effects of exogenous applied ganglio- 

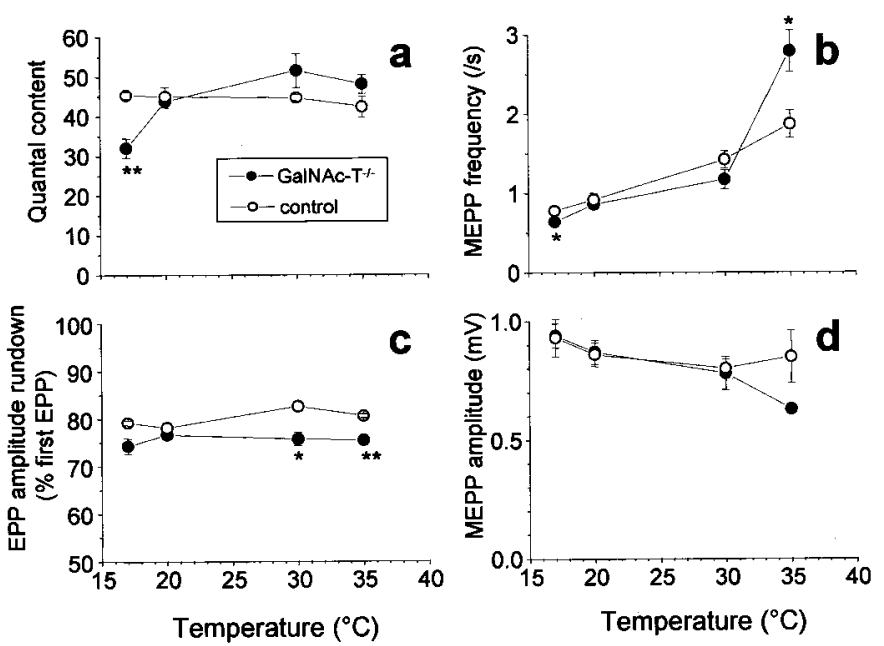

Figure 3. Temperature-dependency of electrophysiological synaptic parameters at GalNAc- ${ }^{-1-}$ neuromuscular junctions. Each temperature group consisted of four to six diaphragms. Controls were wild-type mice, except from the $20^{\circ} \mathrm{C}$ group that consisted of three wild-type and three heterozygous muscles. $a$, A reduction of $29 \%(p<0.01)$ in low-rate $(0.3$ $\mathrm{Hz}$ ) evoked $\mathrm{ACh}$ release was observed at $17^{\circ} \mathrm{C}$ at GalNAc- ${ }^{-1-}$ NMJs, compared with the control value at that temperature. $b$, Spontaneous ACh release was measured as the frequency of MEPPs, the spontaneous uniquantal events. There was a statistically significant increase $(49 \% ; p<$ 0.05 ) of spontaneous release at $35^{\circ} \mathrm{C}$ in GalNAc- ${ }^{-1-}$ NMJs, compared with control. At $17^{\circ} \mathrm{C}$, a slight decrease $(19 \% ; p<0.05)$ was observed. $c$, Rundown of $\mathrm{ACh}$ release during tetanic stimulation $\left(40 \mathrm{~Hz}\right.$ at $20^{\circ} \mathrm{C}, 33 \mathrm{~Hz}$ at the other temperatures). The rundown is given as the average value of the 21st-35th endplate potential (EPP), which forms the plateau phase of the train, and expressed as the percentage of the first EPP in a train. Slightly larger rundown was observed at GalNAc- ${ }^{-/-}$NMJs at 30 and $35^{\circ} \mathrm{C}$, compared with control. $d$, The amplitude of MEPPs did not differ statistically significantly between the genotypes at the different temperatures $\left({ }^{*} p<0.05 ; * *<0.01\right)$.

sides on ion channels in artificial bilayers have been observed to be temperature dependent (Rahmann et al., 1998; Kappel et al., 2000), the effect of temperature variation on basic synaptic electrophysiological properties at NMJs of GalNAc- ${ }^{-/-}$and control mice was investigated. At low temperature $\left(17^{\circ} \mathrm{C}\right)$, the amount of ACh release evoked with $0.3 \mathrm{~Hz}$ nerve stimulation at GalNAc$\mathrm{T}^{-1-}$ NMJs was $29 \%$ lower $(p<0.01)$ than at control NMJs (Fig. $3)$. At higher temperatures studied $\left(20,30\right.$, and $\left.35^{\circ} \mathrm{C}\right)$, no such difference was encountered. ACh release evoked by tetanic (33 $\mathrm{Hz})$ nerve stimulation at 30 and $35^{\circ} \mathrm{C}$ was slightly less well sustained in GalNAc- ${ }^{-/-}$NMJs $(\sim 5 \%$ greater rundown of EPP amplitude; $p<0.05$ ) (Fig. 3). However, in spite of this small difference, the calculated absolute level of the quantal content at the plateau phase of the EPP train (stimulus number 21-35) did not differ between GalNAc-T ${ }^{-/-}$and control NMJs. Spontaneous ACh release in GalNAc- $\mathrm{T}^{-1-}$ NMJs, measured as MEPP frequency, was $19 \%$ lower $(p<0.05)$ than in controls at $17^{\circ} \mathrm{C}$ and $49 \%$ higher $(p<0.05)$ at $35^{\circ} \mathrm{C}$ (Fig. 3$)$.

The $\mathrm{Ca}^{2+}$ dependency of the electrophysiological parameters at GalNAc- ${ }^{-1-}$ and control NMJs was tested in view of the reported ability of gangliosides to sequester $\mathrm{Ca}^{2+}$ and to modulate its flux across neuronal membranes (Ando et al., 1998; Rahmann et al., 1992, 1998). Apart from a less well sustained ACh release at tetanic $(33 \mathrm{~Hz})$ nerve stimulation at high $(5 \mathrm{~mm}) \mathrm{Ca}^{2+}$ (EPP amplitude rundown to 69 vs $75 \% ; p<0.05$ ), none of the measured parameters (quantal content at $0.3 \mathrm{~Hz}, \mathrm{MEPP}$ frequency and amplitude) differed between GalNAc-T ${ }^{-1-}$ and control NMJs at $0.5,2$, and $5 \mathrm{mM} \mathrm{Ca}^{2+}$ (data not shown).
The characterization of the basic electrophysiological properties of GalNAc- ${ }^{-1-}$ NMJs indicates that at nearphysiological conditions ( $2 \mathrm{~mm}$ extracellular $\left.\mathrm{Ca}^{2+}, 35^{\circ} \mathrm{C}\right)$, complex gangliosides are mostly redundant in mice that retain expression of GM3 and GD3.

\section{Botulinum neurotoxin does not block $\mathrm{ACh}$ release at GalNAC-T $^{-/-}$neuromuscular synapses}

Treatment of wild-type hemi-diaphragm preparations with 50 $\mathrm{U} / \mathrm{ml}(\sim 2 \mathrm{ng} / \mathrm{ml})$ BOTOX botulinum neurotoxin type-A readily induced the well known effects at NMJs, drastic reduction of nerve stimulation-evoked $\mathrm{ACh}$ release (quantal content) and spontaneous ACh release (MEPP frequency), to $\sim 1-2 \%$ of the values obtained without the toxin (Fig. 4). In contrast, the quantal content and MEPP frequency of GalNAc- ${ }^{-/-}$NMJs were unchanged after treatment with botulinum neurotoxin (Fig. 4). Botulinum neurotoxin (Calbiochem) up to $600 \mathrm{ng} / \mathrm{ml}$ strongly reduced quantal content and MEPP frequency at wild-type NMJs (by 99.3 and $98.6 \%$, respectively, at $600 \mathrm{ng} / \mathrm{ml}$, compared with the mean values without neurotoxin) but had no effect on these parameters at GalNAc- ${ }^{-1-}$ NMJs (mean quantal content was $62.7 \pm 6.2$ and mean MEPP frequency was $1.47 \pm 0.15 / \mathrm{sec}$ at 600 $\mathrm{ng} / \mathrm{ml} ; n=3$ muscles, $10-15$ NMJs per muscle). These findings prove that one or more complex gangliosides are membrane receptors for botulinum neurotoxin type-A.

\section{GalNAC-T ${ }^{-1-}$ neuromuscular synapses are resistant to the paralytic effects of neuropathy-associated human anti-GQ1b antiserum and monospecific anti-GQ1b mouse mAbs}

Previously, we have described the complement-dependent $\alpha$ LTXlike action of MFS sera and anti-GQ1b/GT1a/GD3 ganglioside mAbs at mouse NMJs (Goodyear et al., 1999; Plomp et al., 1999). To determine whether complex gangliosides, in particular GQ1b, are the primary antigenic targets that mediate the effects of these antibodies, we applied an anti-GQ1b antibody-containing human MFS serum, anti-GQ1b and anti-GD3 monospecific mAbs, and anti-GQ1b/GD3 bispecific mAbs (Table 1) to GalNAc- ${ }^{-1-}$ and control hemi-diaphragms and observed whether the $\alpha$ LTx-like effects appeared after addition of normal human serum as complement source (Fig. 5). The MFS serum and the monospecific anti-GQ1b mAb (EM6) readily induced $\alpha$ LTx-like effects in wildtype NMJs but induced no such effects at GalNAc-T ${ }^{-/-}$NMJs. Conversely, monospecific anti-GD3 mAbs (CGG1 and CGG2) did not induce the $\alpha \mathrm{LTX}$-like effect in control NMJs, whereas they did in GalNAc-T ${ }^{-1-}$ NMJs, although the effect of CGG2 was somewhat less pronounced. The anti-GQ1b/GD3 bispecific mAb (CGM3) potently induced the $\alpha \mathrm{LTx}$-like effects at both GalNAc$\mathrm{T}^{-/-}$and control (GalNAc- $\mathrm{T}^{+/-}$and GalNAc- ${ }^{+/+}$) NMJs.

The extent of paralysis resulting from the $\alpha \mathrm{LTx}$-like effect induced by the mAbs CGM3, EM6, and CGG2 was quantified in isotonic contraction experiments with hemi-diaphragms (Fig. 6). CGM3, as expected from the results of the electrophysiological experiments, caused paralysis of both GalNAc- $\mathrm{T}^{-1-}$ and wildtype muscles. EM6 (anti-GQ1b monospecific) induced partial paralysis in wild-type muscles $(\sim 40 \%)$ but had no effect on GalNAc- ${ }^{-1-}$ muscles. The paralytic effects of CGG1 and CGG2 (anti-GD3 monospecific) were absent or less pronounced in Gal$\mathrm{NAc}^{-1-} \mathrm{T}^{-1-}$ preparations (producing at maximum $50 \%$ paralysis in one of the contraction experiments using CGG1; data not shown), presumably because the $\alpha \mathrm{LTx}$-like effect was somewhat less pronounced and did not lead to severe ACh depletion at motor nerve terminals. 


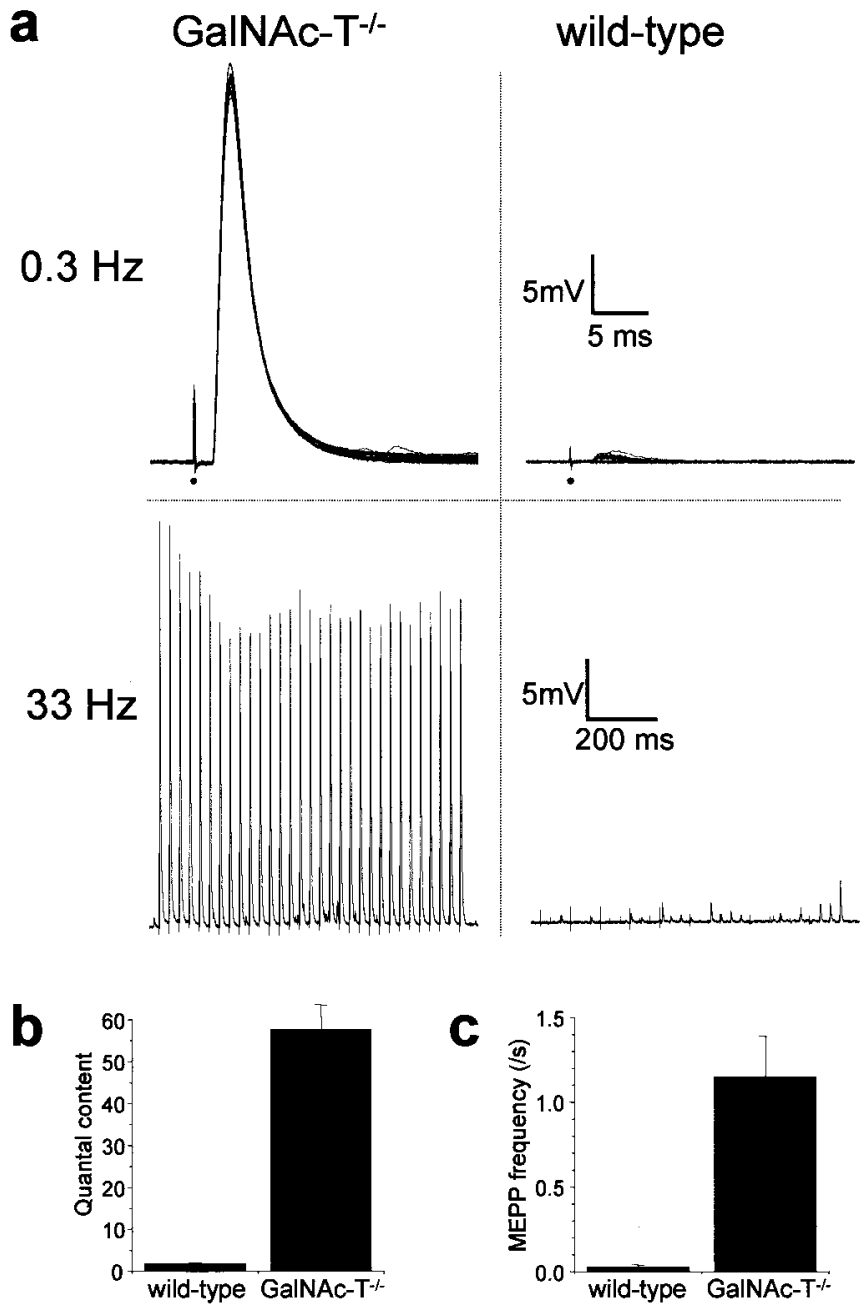

Figure 4. Botulinum neurotoxin lacks effect on ACh release at GalNAc$\mathrm{T}^{-1-}$ neuromuscular junctions. Three GalNAc- $\mathrm{T}^{-1-}$ and three wild-type diaphragms were treated with $50 \mathrm{U} / \mathrm{ml}(\sim 2 \mathrm{ng} / \mathrm{ml})$ botulinum neurotoxin type-A. The resulting effects on ACh release at NMJs were recorded electrophysiologically. At wild-type NMJs the toxin greatly depressed low-rate $(0.3 \mathrm{~Hz})$ and high-rate $(33 \mathrm{~Hz})$ nerve stimulation-evoked $\mathrm{ACh}$ release, as well as the spontaneous release. GalNAc- ${ }^{-1-}$ NMJs were resistant to this action of the toxin. $a$, Typical examples of 0.3 and $33 \mathrm{~Hz}$ evoked EPPs at botulinum neurotoxin-treated GalNAc-T ${ }^{-1-}$ and wildtype NMJs. Thirty $0.3 \mathrm{~Hz}$ EPPs have been superimposed. The moment of nerve stimulation is indicated with a black dot. Note the dramatic decrease in EPP amplitude and the occurrence of failures at wild-type NMJs at both 0.3 and $33 \mathrm{~Hz}$ stimulation frequency. $b$, Average \pm SEM of quantal content of low-rate evoked EPPs. $c$, Average \pm SEM of spontaneous ACh release, measured as uniquantal miniature EPP (MEPP) frequency. Note that values of the GalNAc- ${ }^{-1-}$ NMJ parameters are similar to those found in earlier series without toxin treatment (Fig. 2), indicating that there was not a partial effect of the botulinum neurotoxin at this concentration at GalNAc- ${ }^{-1-}$ NMJs.

\section{Differential deposition of mouse anti-ganglioside mAbs and complement at GalNAc- ${ }^{+/+}$and GalNAc- ${ }^{-/-}$ neuromuscular synapses}

Our previous studies show that occurrence of the $\alpha$ LTx-like effect correlates well with the immunohistological demonstration of antibody and complement deposits at mouse NMJs (O'Hanlon et al., 2001; Jacobs et al., 2002). We analyzed complement factor $\mathrm{C} 3 \mathrm{c}$ deposits in preparations that had been studied electrophysiologically, as describe above (Fig. 7). Treatment with MFS serum or the anti-GQ1b monospecific mAb EM6 induced strong com-
Table 1. Binding specificity for GQ1b and GD3 of the mouse monoclonal antibodies used

\begin{tabular}{llll} 
& & \multicolumn{2}{c}{ Anti-ganglioside activity } \\
\cline { 3 - 4 } Antibody & Isotype & GQ1b & GD3 \\
\hline CGM3 & $\operatorname{IgM} \kappa$ & + & + \\
EM6 & $\operatorname{IgM} \kappa$ & + & - \\
CGG1 & $\operatorname{IgG} 2 \mathrm{~b} \kappa$ & - & + \\
CGG2 & $\operatorname{IgG} 2 \mathrm{~b} \kappa$ & - & +
\end{tabular}

Ganglioside binding was determined as described previously (Goodyear et al., 1999). + , Binding; - , no binding.
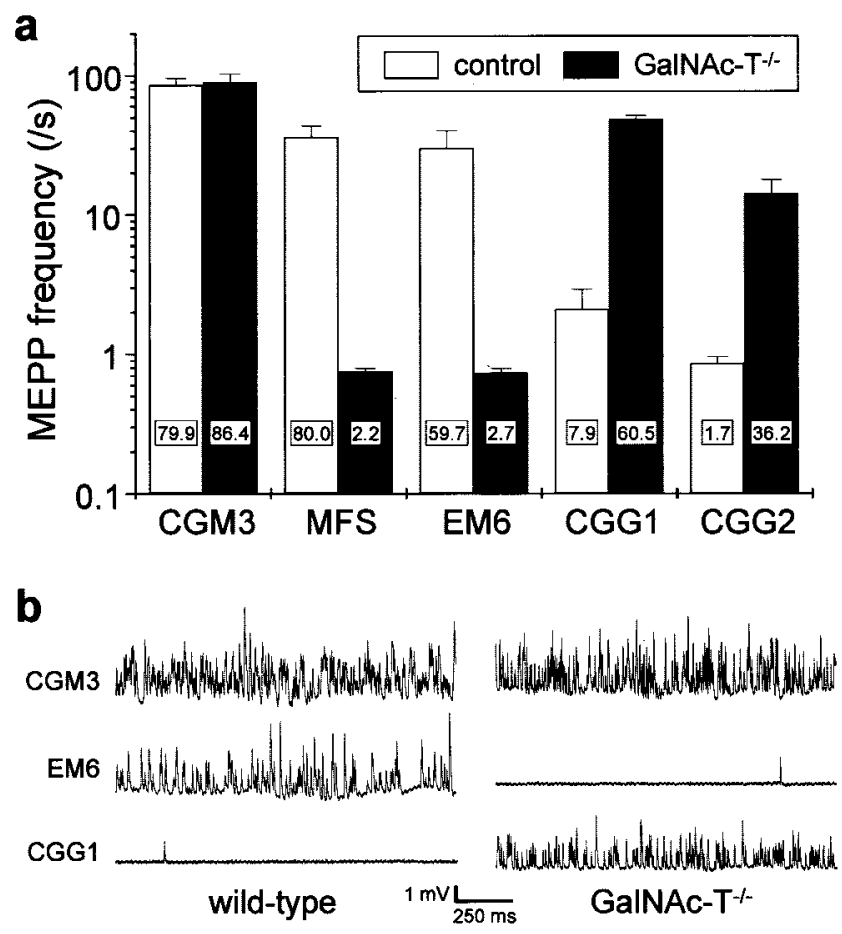

Figure 5. Induction of the $\alpha$-Latrotoxin-like effects at neuromuscular junctions of GalNAc- $\mathrm{T}^{-1-}$ and control mice by anti-ganglioside mouse monoclonal antibodies and Miller Fisher syndrome serum. Spontaneous $\mathrm{ACh}$ release, measured as frequency of miniature endplate potentials $(M E P P)$, was recorded in four to six hemi-diaphragms that were pretreated with $50 \mu \mathrm{g} / \mathrm{ml}$ of the mAb or complement-inactivated Miller Fisher syndrome (MFS) serum (1:2), except for the CGG1 groups that each consisted of three muscles (control group: 2 heterozygous and 1 wild-type mouse). The measurements were done in the presence of normal human serum (1:2) as a source of complement, as described in Materials and Methods. The anti-GQ1b/GD3 specificities of the mAbs used are given in Table 1. $a$, Average values \pm SEM of the MEPP frequencies. The monospecific anti-GQ1b mAb EM6 and the MFS serum induced the $\alpha$ LTx-like effect at wild-type NMJs but not at GalNAc- ${ }^{-1}$ NMJs. Conversely, the monospecific anti-GD3 mAbs CGG1 and CGG2 induced the effect at GalNAc- ${ }^{-1-}$ but not at control NMJs. The bispecific anti-GQ1b/GD3 mAb CGM3 induced the effect at NMJs of all genotypes. The numbers in the bars represent the percentage of NMJs that displayed a MEPP frequency higher than four times the mean of the control value obtained before the mAb or MFS serum incubation (data not shown). $b$, Typical examples of electrophysiological recordings of MEPPs at NMJs treated with the prototype mAb CGM3, EM6, or CGG1.

plement deposition at control NMJs but not at GalNAc-T ${ }^{-/-}$ NMJs. Conversely, exposure of diaphragms to the anti-GD3 monospecific mAb CGG2 resulted in complement deposition at GalNAc- $\mathrm{T}^{-1-}$ but not at control NMJs. The mAb CGM3, reactive with both GD3 and GQ1b and which had brought about the 


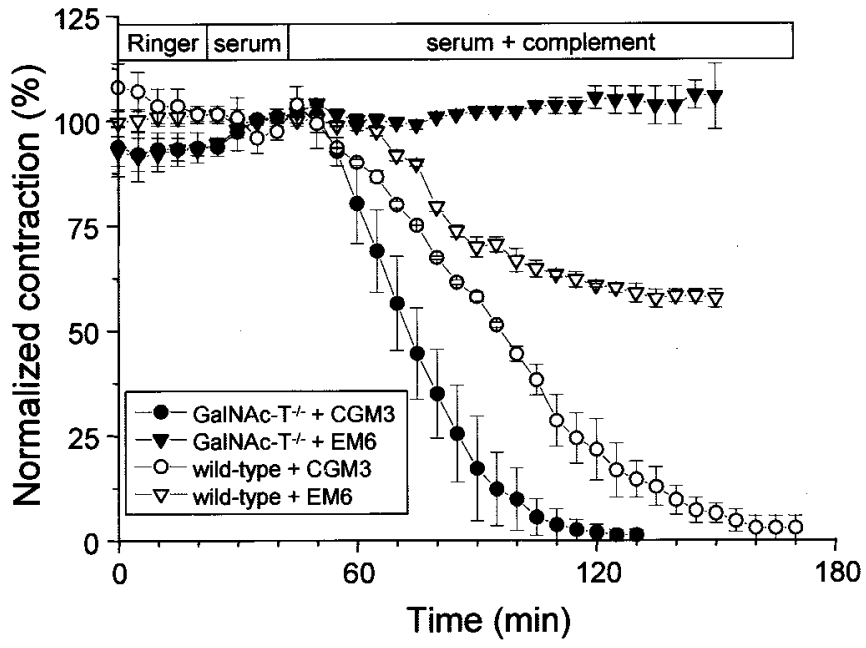

Figure 6. Quantification of the paralysis induced by mono- and multispecific anti-GQ1b mAbs CGM3 and EM6 at GalNAc-T ${ }^{-1-}$ and wildtype muscles. Contraction measurements were done in duplicate on GalNAc- ${ }^{-1-}$ and wild-type muscles pretreated with $50 \mu \mathrm{g} / \mathrm{ml} \mathrm{CGM3}$ or EM6 $\mathrm{mAb}$. The contraction resulting from tetanic nerve stimulation (2 $\mathrm{sec}, 40 \mathrm{~Hz}$ ) was recorded every $5 \mathrm{~min}$. Before addition of complementcontaining normal serum (1:2), contractions were measured during a 25 min period in Ringer's medium and a 20 min period in complementinactivated normal serum (1:2). Symbols represent the peak of the tetanic contraction, expressed as the percentage of the average of the four peak values of the contractions recorded during the incubation period with complement-inactivated serum. The anti-GQ1b/GD3 mAb CGM3 completely paralyzed the muscles from both genotypes, although with a somewhat faster time course in GalNAc- ${ }^{-1-}$ muscles. The monospecific anti-GQ1b mAb EM6 induced partial paralysis ( $40 \%)$ in the wild-type muscles and was ineffective in the GalNAc- ${ }^{-1-}$ muscles.

$\alpha$ LTx-like effect at both GalNAc-T ${ }^{-/-}$and control NMJs, induced complement deposition in both groups.

The presence of immunoglobulin deposits in general correlated with complement deposition. Thus, CGM3 IgM was detected at both GalNAc- ${ }^{-/-}$and control (GalNAc- ${ }^{+/+}$or ${ }^{+/-}$) NMJs, whereas CGG2 IgG was clearly observed at NMJs of GalNAc$\mathrm{T}^{-/-}$tissue but not at control NMJs. EM6 IgM deposition could not be demonstrated at NMJs from either genotype, despite the observation of the $\alpha \mathrm{LTx}$-like effect and complement deposits at GalNAc- ${ }^{+/+}$NMJs, indicating that the amount of tissue-bound EM6 required to produce electrophysiological effects was too small to be detected with our immunohistological methods. These direct immunofluorescence observations on immunoglobulin deposits at NMJs from whole organ in vitro electrophysiological preparations were compared with those made in indirect immunofluorescence studies on NMJs in cryosections from normal GalNAc- $^{+/+}$and GalNAc- ${ }^{-/-}$diaphragms. Quantitative image analysis showed an increase in immunoglobulin staining of GalNAc-T $^{-1-}$ NMJs with CGM3 (169\%), CGG1 (184\%), and CGG2 $(270 \%)$ compared with the staining seen in controls (normalized to $100 \%$ ). As for the direct immunofluorescence, EM6 binding could not be demonstrated by indirect immunofluorescence at NMJs from either genotype. The use of human serum as a complement source in the electrophysiological experiments prevented us from analyzing NMJs for staining with MFS human IgG, as discussed previously (O'Hanlon et al., 2001).

\section{DISCUSSION}

Using null-mutant GalNAc- $\mathrm{T}^{-1-}$ mice lacking complex gangliosides, we investigated possible roles of these gangliosides at pre- synaptic nerve terminals. First, we have demonstrated that complex gangliosides are mostly redundant for neurotransmitter release under physiological conditions and when GM3 and GD3 are abundantly present. Second, we have proven that presynaptic complex gangliosides at mouse NMJs are the biologically relevant receptors for botulinum neurotoxin type-A. Third, we have proven that the complex ganglioside GQ1b is the primary antigenic target for the pathophysiological action at mouse NMJs of anti-GQ1b mouse mAbs and anti-GQ1b antibodies associated with the paralytic human disease MFS. Furthermore, upregulated amounts of GD3 appear to be able to substitute for complex gangliosides in mediating this effect.

\section{Complex gangliosides and synapse function}

Our finding that evoked $\mathrm{ACh}$ release at $\mathrm{NMJs}$ under nearphysiological conditions $\left(2 \mathrm{mM} \mathrm{Ca}^{2+}, 35^{\circ} \mathrm{C}\right)$ is independent of complex gangliosides is surprising. Thus, the synaptosomal studies that have demonstrated increase of transmitter release and $\mathrm{Ca}^{2+}$ influx after bath application of complex gangliosides can now be interpreted as providing evidence that exogenous gangliosides act as positive modulators, rather than providing support for a critical role for endogenous gangliosides as constitutive factors in the process of evoked transmitter release. The observed $49 \%$ increase in spontaneously released ACh quanta at GalNAc- ${ }^{-/-}$ NMJs at $35^{\circ} \mathrm{C}$, measured as MEPP frequency, suggests that complex gangliosides are involved in the release process, but as negative rather than positive regulators. The complex gangliosides GQ1b and GD1a have been shown to play a role in thermal adaptation by reducing the conductance of model ion channels in lipid bilayers at $35^{\circ} \mathrm{C}$ to a larger extent than at $20^{\circ} \mathrm{C}$ (Kappel et al., 2000). If a similar action of GQ1b on P/Q-type $\mathrm{Ca}^{2+}$ channels at the NMJ were to take place, this could explain the increase of spontaneous release from GalNAc- $\mathrm{T}^{-1-}$ motor nerve terminals, compared with normal mice at $35^{\circ} \mathrm{C}$. If this were the case, one might predict increased evoked $\mathrm{ACh}$ release at $\mathrm{GalNAc}^{-/-}$ NMJs. However, the slight increase in quantal content that we observed was not statistically significant. Thus, although complex gangliosides are redundant for evoked $\mathrm{ACh}$ release at $35^{\circ} \mathrm{C}$, they are in some way involved in spontaneous release, which has no functional consequences for NMJ neurotransmission.

We observed a decrease in evoked and spontaneous $\mathrm{ACh}$ release at GalNAc- $\mathrm{T}^{-/-} \mathrm{NMJs}$ at $17^{\circ} \mathrm{C}$, compared with controls at this temperature. This confirms a role for complex gangliosides in synapse function at low temperatures, as suggested by others (Rahmann et al., 1998). This may relate to the peculiar characteristic of complex gangliosides, especially GD1a, of having increased binding capacity for $\mathrm{Ca}^{2+}$ ions at lower temperature, although with lower affinity (Rahmann et al., 1998). This might lead to an increase in $\mathrm{Ca}^{2+}$ availability in the synaptic cleft at lower temperature. Although interesting, this is unlikely to be physiologically relevant in mammals.

The relative redundancy of complex gangliosides for neuronal function is also indicated by the comparatively mild phenotype of GalNAc-T $^{-1-}$ mice (Takamiya et al., 1996; Sheikh et al., 1999). These mice are viable and have a normal life span, intact gross brain morphology, and normal ultrastructure of brain synapses. Young mice (12 weeks old) display no overt behavioral deficits or ataxia but have a slightly reduced neuronal conduction velocity (Takamiya et al., 1996). Close inspection of 12- to 16-week-old mice revealed signs of axonopathy in the CNS and PNS, suggesting that complex gangliosides play a role in myelination and axonal maintenance (Sheikh et al., 1999). This is further sup- 
a

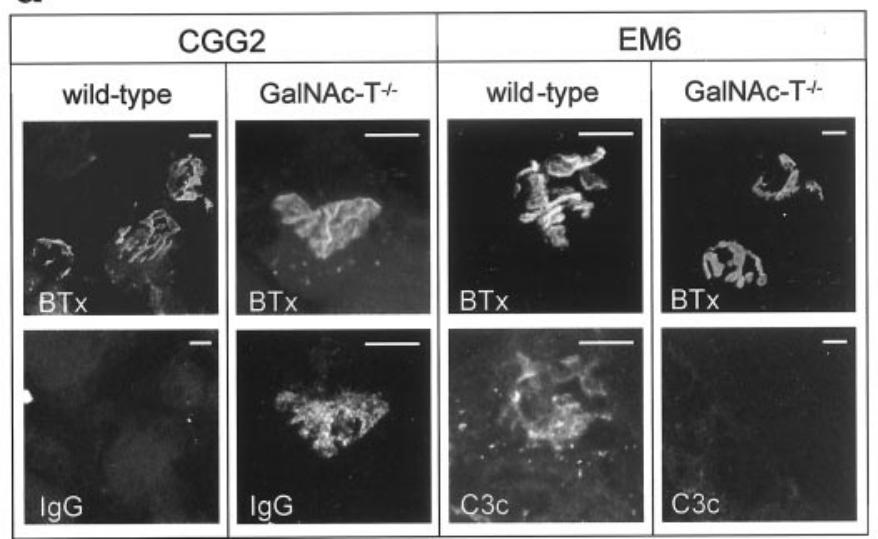

b

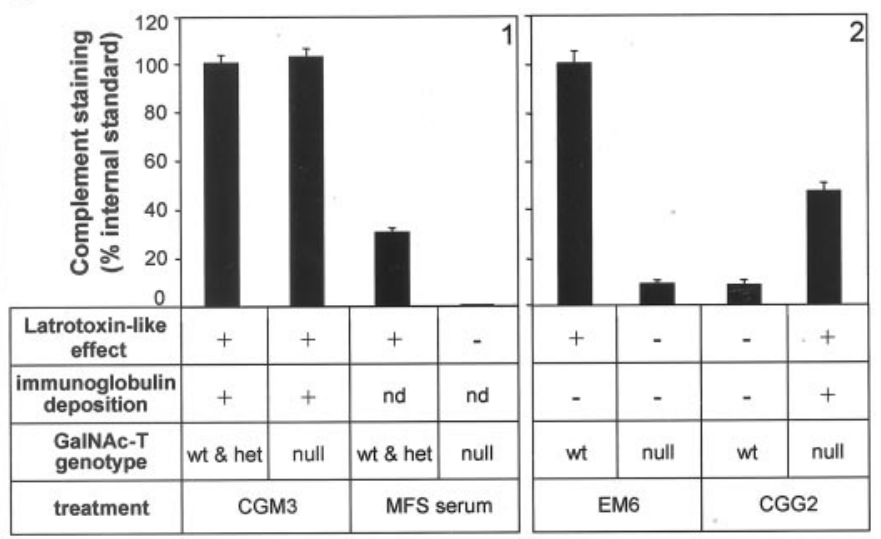

Figure 7. Immunohistological analysis of deposition of complement and antibodies at neuromuscular junctions in GalNAc- $\mathrm{T}^{-/-}$and control muscle preparations treated with MFS serum and mouse monoclonal anti-GQ1b/GD3 antibodies. $a$, Typical examples of pictures taken of deposits of complement and antibody at NMJs in wild-type and GalNAc- ${ }^{-1-}$ preparations that had been treated with monospecific anti-GD3 mAb CGG2 and monospecific anti-GQ1b mAb EM6 $(50 \mu \mathrm{g} / \mathrm{ml})$ and had been studied electrophysiologically (Fig. 5). Shown are NMJs that were double stained with fluorescent $\alpha$-BTx (top row in each panel) and fluorescent antibody against C3c or IgG (bottom row). Scale bars, $10 \mu \mathrm{m}$. BTx, $\alpha$-Bungarotoxin; C3c, complement factor 3c; $I g G$, immunoglobulin G. $b$, Quantitative image analysis indicated that large complement deposits were present only in the samples where the $\alpha$ Latrotoxin-like effect at NMJs had been demonstrated electrophysiologically. As internal standards in the complement-staining quantification, the signal of CGM3-treated control NMJs was used in panel 1 and that of EM6-treated control NMJs was used in panel 2. Qualitative assessment of immunoglobulin showed colocalization of antibody and complement deposition at the NMJs in which the $\alpha$ Latrotoxin-like effect had occurred, except for the monospecific anti-GQ1b mAB EM6, which we could not demonstrate. Apparently, EM6 was deposited in amounts that were not detectable with our immunohistological methods. wt, Wild type; het, heterozygous; null, null-mutant; +, present; -, not present; $n d$, not determined.

ported by the progressive motor deficits observed in aged, 12month-old GalNAc-T ${ }^{-1-}$ mice (Chiavegatto et al., 2000). Cellular studies of GalNAc- ${ }^{-1-}$ cerebellar neurons show aberrant $\mathrm{Ca}^{2+}$ regulating properties, which may contribute to the observed neurological symptoms and axonal pathology (Wu et al., 2001).

The interpretation of our results is complicated by the phenomenon of upregulation of GM3 and GD3 in GalNAc-T ${ }^{-1-}$ mice, which may functionally compensate for the absence of complex gangliosides (Takamiya et al., 1996), thereby making complex gangliosides only conditionally redundant for synaptic function. Moreover, it is possible that overexpression of simple gangliosides is toxic and underlies some neurodeficits in GalNAc- ${ }^{-1-}$ mice. Synaptic function is likely to be affected more severely in the absence of both complex and simple gangliosides. For instance, double knock-out mice that lack both GD3 synthase and GalNAc-T, resulting in the expression of only GM3, exhibit lethal audiogenic seizures and a sudden death phenotype, possibly caused by severe synapse dysfunction (Kawai et al., 2001).

\section{The role of complex gangliosides as botulinum neurotoxin receptors}

GalNAc- $\mathrm{T}^{-/-}$NMJs were resistant to the blocking action of (50 mouse $\mathrm{LD}_{50} / \mathrm{ml}, \sim 2 \mathrm{ng} / \mathrm{ml}$ ) BOTOX botulinum neurotoxin type-A on evoked and spontaneous ACh release. These findings directly linked the presence of endogenous complex gangliosides at presynaptic membranes with a cellular response to botulinum neurotoxin and prove that one or more complex gangliosides are membrane receptors. Earlier studies were all based on in vitro binding and detoxification of botulinum neurotoxin by purified gangliosides and did not prove the membrane receptor hypothesis. A recent toxicological study of the in vivo effects of botulinum neurotoxin in GalNAc- ${ }^{-1-}$ mice showed prolonged survival time (Kitamura et al., 1999). The $\mathrm{LD}_{50}$ in GalNAc- $\mathrm{T}^{-1-}$ mice was calculated, on the basis of survival times, to be $40 \times$ higher than in wild-type controls. This shows that GalNAc- $\mathrm{T}^{-/-}$mice are resistant to but not completely protected from the toxin, possibly because simple gangliosides may substitute as membrane receptors at high toxin concentrations. Although GD3 and GM3 are weak botulinum neurotoxin binders/detoxifiers (Kitamura et al., 1980; Takamizawa et al., 1986), when upregulated they may provide sufficient binding sites for the toxin to have partial effect. Alternatively, a less efficient, nonganglioside receptor might coexist that might be activated only at high botulinum neurotoxin concentrations. However, botulinum neurotoxin at $600 \mathrm{ng} / \mathrm{ml}$ still did not affect ACh release at GalNAc- ${ }^{-1-}$ NMJs, which shows that such receptors at the NMJ, if present at all, require extremely high toxin concentrations.

\section{Presynaptic gangliosides as autoantigens at the neuromuscular synapse}

MFS-associated polyclonal and mouse monoclonal anti-GQ1b antibodies bind to and exert $\alpha \mathrm{LT}$-like effects at mouse NMJs, although the primary antigenic target has not been identified (Goodyear et al., 1999; Plomp et al., 1999; Bullens et al., 2000; O'Hanlon et al., 2001). The simple carbohydrate epitope centered on the terminal NeuNAc $(\alpha 2-8) \operatorname{NeuNAc}(\alpha 2-3)$ Gal-trisaccharide common to GQ1b and GT1a might have cross-reactive glycoprotein analogs such as the sialylated $\alpha$ LTx-receptor CIRL/latrophilin (Davletov et al., 1996). To clarify this issue, we tested the in vitro electrophysiological effects of monospecific and bispecific anti-GQ1b/GD3 mAbs and anti-GQ1b-positive MFS serum on GalNAc- $^{-1-}$ and control NMJs. The lack of effect of the monospecific anti-GQ1b mAb EM6 and the MFS serum on GalNAc$\mathrm{T}^{-/-}$NMJs proved that the presynaptic complex ganglioside GQ1b must be the primary antigenic target of these antibodies.

Interestingly, the bispecific anti-GQ1b/GD3 mAb CGM3 potently induced $\alpha$ LTx-like effects at GalNAc- ${ }^{-/-}$NMJs as well as at control (heterozygous and wild-type) NMJs. Furthermore, the monospecific anti-GD3 mAbs CGG1 and CGG2 were almost ineffective at control NMJs (i.e., only CGG1 induced a very slight 
increase in spontaneous ACh release in a small proportion of the NMJs). At GalNAc-T ${ }^{-1-}$ NMJs, however, these mAbs clearly induced $\alpha$ LTX-like effects. Besides being indirect evidence for upregulated levels of GD3 at motor nerve terminals in GalNAc$\mathrm{T}^{-1-}$ mice, these findings indicate that GD3 can substitute for GQ1b in mediating the $\alpha$ LTx-like effect, provided a sufficiently high level of expression. Our quantitative immunohistological investigations provide evidence of elevated levels of GD3 at GalNAc- $\mathrm{T}^{-/-}$motor nerve endings, by showing increased immunoglobulin staining at NMJs of GalNAc- ${ }^{-/-}$preparations that had been treated with CGM3, CGG1, or CGG2.

The failure to induce electrophysiological $\alpha \mathrm{LTx}$-like effects at GalNAc-T $^{-1-}$ NMJs by the anti-GQ1b monospecific mAb EM6 was confirmed in contraction experiments, where this $\mathrm{mAb}$ induced paralysis only in wild-type preparations. However, the paralysis was only partial, i.e., transmission in part of the NMJs was not blocked by the mAb, in contrast to the complete paralysis induced by CGM3 in both GalNAc- ${ }^{-/-}$and wild-type preparation. It is possible that the unblocked NMJs represent a population that lacks presynaptic GQ1b. Alternatively, it might be that GQ1b is expressed at only very low levels at all NMJs within the preparation and that the electrophysiological effects are just above threshold in part of the population in inducing paralysis. The immunohistological failure to demonstrate IgM deposition at EM6-treated wild-type NMJs preparations supports this possibility. The apparent faster time course of the paralytic action of complement at CGM3-pretreated GalNAc- $\mathrm{T}^{-/-}$preparations in comparison with wild-type controls might be caused by the increased density of GD3 and a consequent increase in CGM3 binding. This is supported by our quantitative immunohistological analysis. Thus, the complex ganglioside GQ1b is indeed the primary antigenic targets for MFS and GBS-related anti-GQ1b antibodies, and high levels of the simple ganglioside GD3 can substitute GQ1b in mediating the $\alpha$ LTx-like effects at the NMJ.

In conclusion, we have presented clear evidence that complex gangliosides form membrane receptors at NMJs for botulinum neurotoxin type-A and neuropathy-associated autoantibodies. However, they are functionally redundant for neurotransmission under physiological conditions.

\section{REFERENCES}

Ahnert-Hilger G, Bigalke H (1995) Molecular aspects of tetanus and botulinum neurotoxin poisoning. Prog Neurobiol 46:83-96.

Ando S, Tanaka Y, Waki H, Kon K, Iwamoto M, Fukui F (1998) Gangliosides and sialylcholesterol as modulators of synaptic functions. Ann NY Acad Sci 845:232-239.

Bakry N, Kamata Y, Simpson LL (1991) Lectins from Triticum vulgaris and Limax flavus are universal antagonists of botulinum neurotoxin and tetanus toxin. J Pharmacol Exp Ther 258:830-836.

Bigalke H, Muller H, Dreyer F (1986) Botulinum A neurotoxin unlike tetanus toxin acts via a neuraminidase sensitive structure. Toxicon 24:1065-1074.

Buchwald B, Weishaupt A, Toyka KV, Dudel J (1998) Pre- and postsynaptic blockade of neuromuscular transmission by Miller-Fisher syndrome $\operatorname{IgG}$ at mouse motor nerve terminals. Eur $\mathrm{J}$ Neurosci 10:281-290.

Bullens RW, O'Hanlon GM, Goodyear CS, Molenaar PC, Conner J, Willison HJ, Plomp JJ (2000) Anti-GQ1b antibodies and evoked acetylcholine release at mouse motor endplates. Muscle Nerve 23: $1035-1043$

Chamberlain LH, Burgoyne RD, Gould GW (2001) SNARE proteins are highly enriched in lipid rafts in PC12 cells: implications for the spatial control of exocytosis. Proc Natl Acad Sci USA 98:5619-5624.

Chiavegatto S, Sun J, Nelson RJ, Schnaar RL (2000) A functional role for complex gangliosides: motor deficits in GM2/GD2 synthase knockout mice. Exp Neurol 166:227-234.

Chiba A, Kusunoki S, Obata H, Machinami R, Kanazawa I (1993) Serum anti-GQ1b IgG antibody is associated with ophthalmoplegia in Miller Fisher syndrome and Guillain-Barre syndrome: clinical and immunohistochemical studies. Neurology 43:1911-1917.
Cruz LJ, Gray WR, Olivera BM, Zeikus RD, Kerr L, Yoshikami D, Moczydlowski E (1985) Conus geographus toxins that discriminate between neuronal and muscle sodium channels. J Biol Chem 260:9280-9288.

Davletov BA, Shamotienko OG, Lelianova VG, Grishin EV, Ushkaryov YA (1996) Isolation and biochemical characterization of a Ca2+independent alpha-latrotoxin-binding protein. J Biol Chem 271: $23239-23245$.

Egorushkina NV, Ratushnyak AS, Egorushkin IV (1993) The influence of exogenous gangliosides on the dynamics of the development of prolonged posttetanic potentiation. Neurosci Behav Physiol 23: $435-438$.

Fisher M (1956) An unusual variant of acute idiopathic polyneuritis (syndrome of ophthalmoplegia, ataxia and areflexia). N Engl J Med 225:57-65.

Furuse H, Waki H, Kaneko K, Fujii S, Miura M, Sasaki H, Ito KI, Kato $\mathrm{H}$, Ando S (1998) Effect of the mono- and tetra-sialogangliosides, GM1 and GQ1b, on long-term potentiation in the CA1 hippocampal neurons of the guinea pig. Exp Brain Res 123:307-314.

Ginalski K, Venclovas C, Lesyng B, Fidelis K (2000) Structure-based sequence alignment for the beta-trefoil subdomain of the clostridial neurotoxin family provides residue level information about the putative ganglioside binding site. FEBS Lett 482:119-124.

Goodyear CS, O'Hanlon GM, Plomp JJ, Wagner ER, Morrison I, Veitch J, Cochrane L, Bullens RW, Molenaar PC, Conner J, Willison HJ (1999) Monoclonal antibodies raised against Guillain-Barre syndromeassociated Campylobacter jejuni lipopolysaccharides react with neuronal gangliosides and paralyze muscle-nerve preparations. J Clin Invest 104:697-708.

Hansson HA, Holmgren J, Svennerholm L (1977) Ultrastructural localization of cell membrane GM1 ganglioside by cholera toxin. Proc Natl Acad Sci USA 74:3782-3786.

Jacobs BC, Bullens RW, O'Hanlon GM, Ang CW, Willison HJ, Plomp JJ (2002) Detection and prevalence of alpha-latrotoxin-like effects of Guillain-Barré syndrome sera. Muscle Nerve 25:549-558.

Kappel T, Anken RH, Hanke W, Rahmann H (2000) Gangliosides affect membrane-channel activities dependent on ambient temperature. Cell Mol Neurobiol 20:579-590.

Kawai H, Allende ML, Wada R, Kono M, Sango K, Deng C, Miyakawa T, Crawley JN, Werth N, Bierfreund U, Sandhoff K, Proia RL (2001) Mice expressing only monosialoganglioside GM3 exhibit lethal audiogenic seizures. J Biol Chem 276:6885-6888.

Kitamura M, Iwamori M, Nagai Y (1980) Interaction between Clostridium botulinum neurotoxin and gangliosides. Biochim Biophys Acta 628:328-335.

Kitamura M, Takamiya K, Aizawa S, Furukawa K, Furukawa K (1999) Gangliosides are the binding substances in neural cells for tetanus and botulinum toxins in mice. Biochim Biophys Acta 1441:1-3.

Lang T, Bruns D, Wenzel D, Riedel D, Holroyd P, Thiele C, Jahn R (2001) SNAREs are concentrated in cholesterol-dependent clusters that define docking and fusion sites for exocytosis. EMBO J 20:2202-2213.

Ledeen RW (1978) Ganglioside structures and distribution: are they localized at the nerve ending? J Supramol Struct 8:1-17.

Maccioni HJ, Daniotti JL, Martina JA (1999) Organization of ganglioside synthesis in the Golgi apparatus. Biochim Biophys Acta 1437: 101-118.

Magleby KL, Stevens CF (1972) A quantitative description of end-plate currents. J Physiol (Lond) 223:173-197.

Marxen P, Fuhrmann U, Bigalke H (1989) Gangliosides mediate inhibitory effects of tetanus and botulinum A neurotoxins on exocytosis in chromaffin cells. Toxicon 27:849-859.

McLachlan EM, Martin AR (1981) Non-linear summation of end-plate potentials in the frog and mouse. J Physiol (Lond) 311:307-324.

O'Hanlon GM, Plomp JJ, Chakrabarti M, Morrison I, Wagner ER, Goodyear CS, Yin X, Trapp BD, Conner J, Molenaar PC, Stewart S, Rowan EG, Willison HJ (2001) Anti-GQ1b ganglioside antibodies mediate complement-dependent destruction of the motor nerve terminal. Brain 124:893-906.

Plomp JJ, Molenaar PC, Ohanlon GM, Jacobs BC, Veitch J, Daha MR, Vandoorn PA, Vandermeche FGA, Vincent A, Morgan BP, Willison HJ (1999) Miller Fisher anti-GQ1b antibodies: alpha-latrotoxin-like effects on motor end plates. Ann Neurol 45:189-199.

Rahmann H, Probst W, Muhleisen M (1982) Gangliosides and synaptic transmission. Jpn J Exp Med 52:275-286.

Rahmann H, Schifferer F, Beitinger H (1992) Calcium-ganglioside interactions and synaptic plasticity: effect of calcium on specific ganglioside/ peptide (valinomycin, gramicidin A)-complexes in mixed mono- and bilayers. Neurochem Int 20:323-338.

Rahmann H, Jonas U, Kappel T, Hilderbrandt H (1998) Differential involvement of gangliosides versus phospholipids in the process of temperature adaptation in vertebrates. A comparative phenomenological and physicochemical study. Ann NY Acad Sci 845:72-91.

Ramirez OA, Gomez RA, Carrer HF (1990) Gangliosides improve syn- 
aptic transmission in dentate gyrus of hippocampal rat slices. Brain Res 506:291-293.

Roberts M, Willison H, Vincent A, Newsom-Davis J (1994) Serum factor in Miller-Fisher variant of Guillain-Barre syndrome and neurotransmitter release. Lancet 343:454-455.

Schiavo G, Benfenati F, Poulain B, Rossetto O, Polverino de Laureto P, DasGupta BR, Montecucco C (1992) Tetanus and botulinum-B neurotoxins block neurotransmitter release by proteolytic cleavage of synaptobrevin. Nature 359:832-835.

Schiavo G, Matteoli M, Montecucco C (2000) Neurotoxins affecting neuroexocytosis. Physiol Rev 80:717-766.

Sheikh KA, Sun J, Liu Y, Kawai H, Crawford TO, Proia RL, Griffin JW, Schnaar RL (1999) Mice lacking complex gangliosides develop Wallerian degeneration and myelination defects. Proc Natl Acad Sci USA 96:7532-7537.

Simons K, Ikonen E (1997) Functional rafts in cell membranes. Nature 387:569-572.

Simpson LL (1989) Botulinum neurotoxin and tetanus toxin. San Diego: Academic.

Simpson LL, Rapport MM (1971a) Ganglioside inactivation of botulinum toxin. J Neurochem 18:1341-1343.

Simpson LL, Rapport MM (1971b) The binding of botulinum toxin to membrane lipids: phospholipids and proteolipid. J Neurochem 18:1761-1767.

Singh AK, Harrison SH, Schoeniger JS (2000) Gangliosides as receptors for biological toxins: development of sensitive fluoroimmunoassays using ganglioside-bearing liposomes. Anal Chem 72:6019-6024.

Svennerholm L (1994) Designation and schematic structure of gangliosides and allied glycosphingolipids. Prog Brain Res 101:XI-XIV.

Takamiya K, Yamamoto A, Furukawa K, Yamashiro S, Shin M, Okada
M, Fukumoto S, Haraguchi M, Takeda N, Fujimura K, Sakae M, Kishikawa M, Shiku H, Furukawa K, Aizawa S (1996) Mice with disrupted GM2/GD2 synthase gene lack complex gangliosides but exhibit only subtle defects in their nervous system. Proc Natl Acad Sci USA 93:10662-10667.

Takamizawa K, Iwamori M, Kozaki S, Sakaguchi G, Tanaka R, Takayama H, Nagai Y (1986) TLC immunostaining characterization of Clostridium botulinum type A neurotoxin binding to gangliosides and free fatty acids. FEBS Lett 201:229-232.

Tanaka Y, Waki H, Kon K, Ando S (1997) Gangliosides enhance KClinduced $\mathrm{Ca} 2+$ influx and acetylcholine release in brain synaptosomes. NeuroReport 8:2203-2207.

Wiegandt $H$ (1967) The subcellular localization of gangliosides in the brain. J Neurochem 14:671-674.

Wieraszko A, Seifert W (1985) The role of monosialoganglioside GM1 in the synaptic plasticity: in vitro study on rat hippocampal slices. Brain Res 345:159-164.

Willison HJ, O'Hanlon GM (1999) The immunopathogenesis of Miller Fisher syndrome. J Neuroimmunol 100:3-12.

Willison HJ, Paterson G, Veitch J, Inglis G, Barnett SC (1993) Peripheral neuropathy associated with monoclonal $\mathrm{IgM}$ anti-Pr2 cold agglutinins. J Neurol Neurosurg Psychiatry 56:1178-1183.

Wu G, Xie X, Lu ZH, Ledeen RW (2001) Cerebellar neurons lacking complex gangliosides degenerate in the presence of depolarizing levels of potassium. Proc Natl Acad Sci USA 98:307-312.

Yuki N, Taki T, Inagaki F, Kasama T, Takahashi M, Saito K, Handa S, Miyatake T (1993) A bacterium lipopolysaccharide that elicits Guillain-Barre syndrome has a GM1 ganglioside-like structure. J Exp Med 178:1771-1775 